\title{
Evaluation of Information Contained in Drug Advertisement and Promotion Materials in Nigeria
}

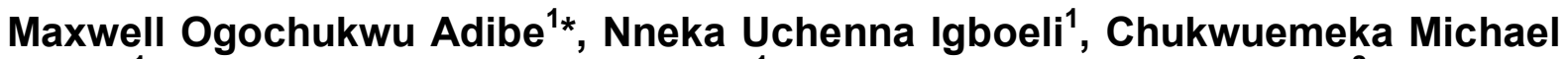 \\ Ubaka $^{1}$, Patrick Obinna Udeogaranya ${ }^{1}$, Nkejah Precious Onwudiwe ${ }^{2}$ and Obo \\ Okokon Ita ${ }^{1}$ \\ ${ }^{1}$ Department of Clinical Pharmacy and Pharmacy Management, ${ }^{2}$ Department of Pure and Industrial Chemistry, University of \\ Nigeria, Nsukka
}

*For correspondence: Email: maxwell.adibe@unn.edu.ng, maxwell.adibe@gmail.com, maxolpharmacia@yahoo.com; Tel: +2348037781479

\begin{abstract}
Purpose: To evaluate the physical characteristics (size, legibility or readability) and the completeness of information in drug package leaflets/inserts and drug promotional brochures in Nigeria.

Methods: Three hundred materials (drug information leaflets and brochures) were collected from various community pharmacies, private and governmental clinics and from various pharmaceutical distributor or representatives from different states of Nigeria. Two independent panels sorted and evaluated the information found in them and differences were resolved by consensus.

Results: This study revealed that $80.7 \%$ of the materials evaluated were leaflets while brochures accounted for $18 \%$. The physical characteristics of the materials showed that $58.7,31.3$ and $89.0 \%$ of the materials were sizeable, readable/legible and had adequate color contrast respectively. Most of the materials were written in English (78.7\%), English and French $17.3 \%$, English and Arabic accounted for only $4 \%$. Description of indications for which the drugs were used was mentioned in $30.3 \%$ of materials. Other contents of the materials were mechanism of action (70.3\%), overdoses information $(55.0 \%)$, drug interaction (51.3\%), pharmacokinetics (36.3\%) and revision date of the information (21.0\%).

Conclusion: This study reveals that advertising materials used in promoting drugs in Nigeria have incomplete information and the physical characteristics of the materials are not adequate. It seems that drug industries at present mainly aim at increasing sales rather than promoting health care. Information in some pharmaceutical brochures exaggerated the benefits of the drug and downplayed risks associated with the drugs.
\end{abstract}

Keywords: Drug information, Drug leaflet, Drug promotion brochure, Nigeria, Advertizing materials

Tropical Journal of Pharmaceutical Research is indexed by Science Citation Index (SciSearch), Scopus, International Pharmaceutical Abstract, Chemical Abstracts, Embase, Index Copernicus, EBSCO, African Index Medicus, JournalSeek, Journal Citation Reports/Science Edition, Directory of Open Access Journals (DOAJ), African Journal Online, Bioline International, Open-J-Gate and Pharmacy Abstracts

\section{INTRODUCTION}

Drug promotion, according to World Health Organization (WHO), refers to all the informational and persuasive activities of the pharmaceutical industries, the effect of which is to induce prescription, supply, purchase, and use of medicinal drugs [1]. Such persuasive activities includes the activities of medical representatives, direct-to-physician promotion (DTPP), provision of gifts and drug samples, drug package inserts, direct-to-consumer advertisements (DTCA), periodicals, telemarketing, holding of conferences, symposium and scientific meetings, 
sponsoring of medical education, advertisements through radio, TV, pamphlet and organizing promotional trials [2].

In recent times however, $\mathrm{WHO}$ and some NGOs are becoming worried about the unethical and inappropriate approach to the promotion of drugs, devices and other pharmaceutical products. As at 1997, in a seminar on WHO's Ethical Criteria for Medicinal Drug Promotion, there was a firm agreement that inappropriate promotion of medicinal drugs is still a problem both in developing and developed countries [3]. Promotional materials, according to WHO's Ethical Criteria for Medicinal drug Promotion, should include the name of the active ingredient, brand name, content of active ingredient per dosage form or regimen, other ingredients known to cause problems, approved therapeutic uses, dosage form or regimen, side effects, contraindications, major interactions, management in case of overdose or toxicity, storage conditions, pharmacokinetic profile, use in pregnancy and lactation, name and address of manufacturers or distributor, and reference to scientific literature. Such information is believed to increase public's awareness of diseases and other health conditions. This will help people to take responsibility for their own health by teaching them how to recognize disease, and motivate them to seek medical attention for condition that might, otherwise be left undiagnosed and untreated. Unfortunately, many drug promotional materials do not meet this standard. This research work is therefore aimed at evaluating the information in drug promotional brochures and medicine information leaflets.

\section{EXPERIMENTAL}

\section{Sample collection}

This was a descriptive study based on critical appraisal of drug promotional brochures and leaflets. Three hundred materials (drug package leaflet $=242$ and promotional brochures $=58$ ) were collected from community pharmacies, private and governmental clinics and various pharmaceutical companies in different states of Nigeria. These leaflets and brochures were sorted to avoid selecting more than one particular material. All the drug information materials for promotion of prescription and nonprescription drugs available and within the reach of the researchers at the time of this study were collected and evaluated. Evaluated materials included 242 leaflets, and 58 brochures issued by pharmaceutical companies. The whole materials were given an identification number for easy evaluation based on their therapeutic classes.

\section{Size, readability and color contrast test}

The size, the readability or legibility and color contrast of the information materials were evaluated. In Nigeria, there are no regulations concerning the readability of labeling and package inserts of medicinal products [4] and as a result, we hypothesized that a material was sizable if it was equal or greater than half of $\mathrm{A} 4$ paper (about $8.27 \times 5.80$ inches); readable or legible if the font size is equal to or more than 10; good color contrast if the material had white background with black, blue, or green printing. The size, legibility, color contrast and drug information contained in these materials were evaluated by two independent panels (two pharmacists). The information examined comprises of the following: Name of condition treated with the promoted drug, Information about the condition, Symptoms associated with the condition, Conditions prevalence, Misconception about the condition, Risk factors associated with the condition, Information about the treatment, Drug generic name, Mechanism of action, Composition, Onset time, Dosage regimen, Duration of treatment, Adverse effects, Precautions, Drug-drug and drug-food interactions, Over dosage, Contraindication, Lifestyle or behavioral changes necessary, Available competing treatment, Storage condition and Date of revision.

The information was assessed using current Nigerian drug Index (N.D.I) and British National Formulary (BNF) in line with WHO Ethical Criteria for Medicinal Drug Promotion [1], each of the panels evaluated the materials to determine the presence or absence of information about specific condition for which the drug was promoted and about the drug profile. After the evaluation, the two panels resolved differences by consensus.

\section{Data analysis}

Data analysis was carried out using SPSS version 16. The analysis was based on classification of content into the type of advertising materials and place of origin, i.e., difference in information of imported and locally produced. Drugs information studied were the same as those distributed in other states, thus the sample subjected to analysis is representative of the situation in the whole country. 


\section{RESULTS}

This study revealed that $80.7 \%$ of the materials evaluated were leaflets while brochures accounted for $18 \%$. The physical characteristics of the materials showed that 58.7, 31.3 and 89.0 $\%$ of the materials were sizeable, readable/legible and had adequate color contrast respectively. Most of the materials were written in English $(78.7 \%)$, English and French $17.3 \%$, English and Arabic accounted for only $4 \%$. Description of indications for which the drugs were used was mentioned in $30.3 \%$ of materials. Other contents of the materials were mechanism of action (70.3\%), overdoses information (55.0 $\%)$, drug interaction (51.3\%), pharmacokinetics $(36.3 \%)$ and revision date of the information (21.0\%), as shown in Table 1.

The type of incomplete information observed in the leaflet include lack of side effect $38(15.7 \%)$, contraindication $58 \quad(23.9 \%) \quad$ overdose information $131(54.1 \%)$, storage condition 76 (31.4\%), drug interactions 138 (57.0\%), precautions/cautions $51 \quad(21.0 \%)$, lifestyle changes $232(95.8 \%)$. Overall, information about treatment included in the promotional brochures scrutinized during the study period can be considered as unsatisfactory except for lifestyle modification 56 (96.5\%).

The brochures and leaflets covered various therapeutic classes including cardiovascular, gastrointestinal, neurological, diabetes mellitus, infectious diseases, malaria, multivitamin and asthma medications. The drugs included 42 brand names and 27 generics. These drugs covered Antibiotics, $23.7 \%$; Antimalaria, $9.3 \%$; Multivitamin, $13.3 \%$; Analgesics, $14.3 \%$; Antifungal $6.7 \%$; Antihypertensive, $3.3 \%$; Antidiabetes, $4 \%$; GIT drugs, $3.7 \%$; Gynecological drugs, $4.1 \%$; Antihistamine, $3.7 \%$; Anti-ulcer, $3.3 \%$; Antitussive/expectorant, $2.0 \%$; Antiasthmatic, $3 \%$; Anticancer, $0.7 \%$; C.N.S drugs, $2.0 \%$; Antiepileptic, $0.3 \%$ and Anthelmintics, $3.0 \%$ cardiovascular drugs, 0.7 $\%$; Table 2.

Table 1: Physical characteristics and therapeutic information of the promotion materials

\begin{tabular}{|c|c|c|c|}
\hline \multirow[t]{2}{*}{ Information } & \multicolumn{2}{|c|}{ Promotional Materials } & \multirow[t]{2}{*}{ Total $(n=300)$} \\
\hline & Leaflet $(n=242)$ & Brochure (n=58) & \\
\hline \multicolumn{4}{|l|}{ Physical characteristics } \\
\hline sizeable material & $142(58.7)$ & $34(58.6)$ & $176(58.7)$ \\
\hline Legibility or readable materials & $76(31.4)$ & $18(31)$ & $94(31.3)$ \\
\hline Adequate color Contrast & $215(88.8)$ & $52(89.6)$ & $267(89.0)$ \\
\hline \multicolumn{4}{|l|}{ Place of origin } \\
\hline Local & $41(16.9)$ & $2(3.4)$ & $43(14.3)$ \\
\hline Imported & $201(83.1)$ & $26(96.6)$ & $227(85.7)$ \\
\hline \multicolumn{4}{|l|}{ Language } \\
\hline English & $178(73.6)$ & $58(100.0)$ & $236(78.7)$ \\
\hline English and French & $53(21.9)$ & $0(0.0)$ & $53(17.7)$ \\
\hline English and others & $11(4.5)$ & $0(0.0)$ & $11(3.7)$ \\
\hline \multicolumn{4}{|l|}{ Target } \\
\hline Physicians & $5(2.1)$ & $58(100.0)$ & $63(21.0)$ \\
\hline Consumers & $237(93.7)$ & $0(0.0)$ & $237(79.0)$ \\
\hline \multicolumn{4}{|l|}{ Drug name } \\
\hline Brand & $40(16.5)$ & $2(3.4)$ & $42(13.7)$ \\
\hline Generic & $25(10.3)$ & $2(3.4)$ & $27(9.0)$ \\
\hline Both & $177(73.1)$ & $54(93.1)$ & $231(77.0)$ \\
\hline \multicolumn{4}{|l|}{ Therapeutic information } \\
\hline Indications & 220 (90.9) & $58(100)$ & $278(92.7)$ \\
\hline Mechanism of action & $157(64.9)$ & $54(93.1)$ & $211(70.3)$ \\
\hline Overdose information & $111(46.1)$ & $54(93.1)$ & $165(55.0)$ \\
\hline Contraindications & $184(76.0)$ & $53(91.4)$ & $237(79.0)$ \\
\hline Compositions / ingredients & $218(90.1)$ & $54(93.1)$ & $272(90.7)$ \\
\hline Side effects / adverse effects & 204 (84.3) & $55(94.8)$ & 259 (86.3) \\
\hline Dosage regimen & 232 (95.9) & 56 (98.2) & $288(96.0)$ \\
\hline Precautions / cautions & $191(79.3)$ & $54(93.1)$ & $245(81.7)$ \\
\hline Drug interaction & $104(43.0)$ & $50(86.2)$ & $154(51.3)$ \\
\hline Storage condition & 166 (68.9) & $48(82.8)$ & $214(71.3)$ \\
\hline Pharmacokinetics & $59(24.5)$ & $50(86.2)$ & 109 (36.3) \\
\hline Lifestyle & $10(4.1)$ & $2(3.4)$ & $12(4.0)$ \\
\hline Date of last revision & $22(9.1)$ & $41(70.7)$ & 63 (21.0) \\
\hline
\end{tabular}


Table 2: Classes of drugs whose promotion materials were mostly encountered

\begin{tabular}{lccc}
\hline Classes of drug & Leaflet $\mathbf{( n = 2 4 2 )}$ & Brochure $(\mathbf{n}=\mathbf{5 8})$ & Total \\
\hline Antibiotic & $59(24.4)$ & $14(24.1)$ & $73(23.7)$ \\
Analgesic & $35(14.5)$ & $10(17.3)$ & $45(14.3)$ \\
Multivitamin & $39(16.1)$ & $2(3.4)$ & $41(13.3)$ \\
Anti-malarial & $25(10.3)$ & $4(6.9)$ & $29(9.3)$ \\
Antifungal & $9(3.7)$ & $11(19.0)$ & $20(6.7)$ \\
Anti-diabetics & $12(5.0)$ & $0(0.0)$ & $12(4.0)$ \\
Gynecological drugs & $7(2.9)$ & $5(4.0)$ & $12(4.0)$ \\
Antihypertensive/ & $10(41.0)$ & $0(0.0)$ & $10(3.3)$ \\
GIT (Spasmodic and Antispasmodics) & $8(3.3)$ & $8(13.8)$ & $16(5.3)$ \\
Antihistamine & $9(4.7)$ & $2(3.2)$ & $11(3.7)$ \\
Anti ulcer & $9(3.7)$ & $1(1.7)$ & $10(3.3)$ \\
Anthelmintics & $8(3.3)$ & $1(1.3)$ & $9(3.0)$ \\
Anti-tussive/expectorant & $6(2.5)$ & $0(0.0)$ & $6(2.0)$ \\
Anti-asthmatics & $6(2.5)$ & $0(0.0)$ & $6(2.0)$ \\
C.N.S active drugs & $6(2.5)$ & $0(0.0)$ & $6(2.0)$ \\
Anticancer & $2(0.8)$ & $0(0.0)$ & $2(0.7)$ \\
Antiepileptic & $1(0.4)$ & $0(0.0)$ & $1(0.3)$ \\
\hline
\end{tabular}

\section{DISCUSSION}

The result of this study revealed that most of the leaflets were directed to the consumers while the brochures were mainly physician-targeted. Our study also revealed that none of the promotional materials had all the necessary information as stipulated by WHO's Ethical Criteria for Medicinal Drug Promotion [1]. Quite a lot of studies have shown that many printed advertisements and drug promotional materials do not meet regulations and guidelines in force in various countries especially in developing countries. A study from Brazil noted that approximately $75 \%$ of the advertisements did not comply with regulations in Brazil [5]. Similarly in a study carried out in Nepal [6], none of the promotional materials had all the necessary information when compared with WHO's Ethical Criteria for Medicinal Drug Promotion [3]. Similarly, consumers' reports in the U.S.A have shown that prescription drug information directed to patient and physicians were of little educational value [7]. Most marketing communication effort by pharmaceutical manufacturers concentrates on direct-to-patient-advertisement (DTPA) via drug promotional brochures and pharmaceutical sales representatives. The pharmaceutical industry invests large sums of money every year aimed at influencing the prescribing habits of physicians because, to a large degree, physicians regulate the amount of drugs bought by the consumers. Meanwhile, consumers seem not to constitute any major concern to the pharmaceutical industries as the direct-to-consumer information were rather superficial and none educational [7]. The results of this study is in congruence with work carried out in Pakistan where promotional materials were adjudged to be misleading, unjustifiable, exaggerated, ambiguous, false, and controversial [8].

\section{Drug package leaflets, promotional materials and consumer education}

The increase in direct-to-consumer advertizing (DTCA) was driven in part by manufacturers' need to be more aggressive at marketing their products and by regulators' willingness to provide consumers with new information in the hopes of providing further education [9]. Ultimately, the argument that DTCA promotions educate the public about medical conditions and their treatments hinges on the quality of drug information available to consumers through advertising. However, our analyses found that educational quality is highly variable among the leaflets. None of them contained any information about the symptoms of the condition and clarifications about the condition-related misconception. Inclusion of the date of revision of the materials was $9.1 \%$ in the leaflets. Despite the fact that health lifestyle and supportive behavior are important at all stages of the disease process, only $4.1 \%$ described some of these changes in lifestyle that should be considered by patients using such medications. Healthy lifestyle and supportive behavior of the patient are important at all stages of the disease process and management but this information was lacking in most of the leaflets. Contrary to claims that promotional materials serve an educational purpose, our analysis show that the promotional material sampled provide limited information about the causes of diseases or who may be at risk. Some of them portray patients as people, who without the medications have lost control over their social, emotional or physical lives. A study has reported that some promotional materials have limited educational value and may oversell the benefits of drugs in ways that might conflict with promoting 
population health [10]. In this study none of the materials listed behavioral changes that can improve the patient health either independently or in concert with the drug treatment. Behavioral recommendations such as diet, exercise, sleep pattern weight loss or smoking cessation are equally well known and are issues that must also be understood and addressed to ensure that the patient have every chance of achieving optimum health gain from any disease management strategy [11]. Negligence of behavioral changes that could significantly contribute to health of the patients seems to be a common defect of marketing promotional materials everywhere.

Health literacy is defined as "the degree to which individuals have the capacity to obtain, process, and understand basic health information and services needed to make appropriate health decisions". Hence the consumer must understand the language in which the information on health is being presented. One strategy of making medicine information more readable and useful is by providing them in consumer's primary language [12]. English language is not the native language of Nigeria but this study revealed that none of the promotional materials was produced in the user's primary language (Igbo, Hausa or Yoruba). Most of the bilingual leaflets are in English and French, and only few Nigerians can read French. This can affect readability as a number of consumers can only read and understand their primary language. For a material to be considered educative, accurate and non-misleading, the language should be comprehensible to the consumers.

\section{Limitations of the study}

Our study was subject to the following limitations, and the results were interpreted in this light: The study included only the leaflets and promotional materials which were available and accessible to the researchers during the period of the study, it remains possible that inclusion of these available materials in the study may have differed in some important way from those which were not included. Reviewers' (two independent panels) bias was a potential limitation due to differences in reviewers' attitude, though we believe that this effect should be minimal as there was a guideline/template for guided judgment and differences in reviewers' opinions were resolved by consensus.

\section{CONCLUSION}

This study reveals that advertising materials used in promoting drugs in Nigeria have incomplete information and the physical characteristics of the materials are not adequate. Information in some pharmaceutical brochures exaggerated the benefits of the drug and downplayed risks associated with the drugs. This issue is of major concern because in a country like Nigeria, drug promotional materials are considered one of the major sources of drug information. Therefore, there is urgent need for the Pharmaceutical advertisements to be subjected to more strict regulations before being published. Health care providers should be cautious about the reliability of information in all drug leaflets and promotional materials and should follow principles of evidence based medicine in assessing the validity of information on targeted drugs.

\section{REFERENCES}

1. World Health Organization. Ethical criteria for medicinal drug promotion. Geneva, 1988. [cited 2013 October 4] Available from: http://apps.who.int/medicine docs/documents/whozip08e/whozip08e.pdf\&sa=U\&ei $=s 8 \_z U r D z M o b 8 y g O 0 m o L o B w \& v e d=0 C A 0 Q F j A B \& s i$ $g 2=o X Z W N S c 75 D y U A v W M O P W U 7 g \& u s g=A F Q j C N$ EwjZu8a8y_etpi6FbxiMpljjqBIQ

2. Lai A. Pharmaceutical drug promotion: how it is being practiced in India? J Assoc Physicians India 2001; 49: $266-273$

3. Oshikoya KA, Oreagba I, Adeyemi O. Sources of drug information and their influence on the prescribing behavior of doctors in a teaching hospital in Ibadan, Nigeria. Pan Afr Med J 2011; 9:13. [cited 2013 October 4] Available from: http://www.panafricanmed-journal.com/content/article/14/74/full/

4. Auta A, Shalkur D, Dayom DW, Banwat SB. Readability of malaria medicine information leaflets in Nigeria. Trop J Pharm Res 2011; 10(5): 631-635.

5. Wzorek LF, Correr CJ, Trindade ACB, Pontarolo R. Analysis of medicine advertisement produced in Brazil. Pharm Pract 2007; 5(3): 105-108.

6. Alam K, Shah AK, Ojha P, Palaian S, Shankar PR. Evaluation of drug promotional materials in a hospital setting in Nepal. South Med Rev 2009; 1(2): 2-6.

7. Consumer Association. Promotion of Prescription Drugs: Public Health or Private Profit? Policy Report. Great Britain, Consumer Association, 2001.[Cited 2013 October 4]. Available from: http://books.google. com.ng/books/about/promotion_of_prescription_Drug s.html?id $=d H Z D H Q A A C A A J \&$ redir_esc $=y$

8. Rohra DK, Gilani AH, Memon IK, Perven G, Kham MT, Zafar $H$, Kurmar R. Critical evaluation of the claims made by pharmaceutical companies in drug promotional material in Pakistan. $J$ Pharm Pharmaceut Sci 2006; 9: 50-59.

9. Wilkes MS, Bell RA, Kravitz RL. Direct-to-consumer drug advertizing: trends, impact and implications. Health Aff 2000; 19(2): 110-128.

Trop J Pharm Res, March 2015; 14(3): 543 
10. Brater DC, Daily WJ. Clinical Pharmacology in the middle Ages: Principles that presage the 21st Century. Clin Pharmacol Ther 2000; 67(5): 447-450.

11. Walker R. Medication adherence. In: Barber N. and Wilson A (Eds). Churchill's Clinical Pharmacy Survial
Guide. Edinburgh, Churchills Living stone, 1999: 111-116.

12. Buck ML. Providing patients with written medication information. Ann Pharmacother 1998; 32: 962-969. 